\title{
Sporadik Bir Bölgede: Dört İmport Sitma Olgusu
}

\author{
Four Malaria-Import Patterns: Sporadic Region
}

\section{Emine Parlak ${ }^{1}$ Ayşe Ertürk², Yasemin Çayır, Mehmet Parlak}

${ }^{1}$ Atatürk Üniversitesi Tıp Fakültesi, Enfeksiyon Hastalıkları ve Klinik Mikrobiyoloji Anabilim Dalı, Erzurum, Türkiye ${ }^{2}$ Recep Tayyip Erdoğan Üniversitesi Eğitim ve Araştırma Hastanesi, Enfeksiyon Hastalıkları Kliniği, Rize, Türkiye ${ }^{3}$ Atatürk Üniversitesi Tıp Fakültesi, Aile Hekimliği, Erzurum, Türkiye

\section{ÖZET}

Sıtma tarihte olduğu gibi günümüzde de önemli bir sağlık sorunu oluşturan paraziter bir infeksiyon hastalığıdır. Ülkemizde en fazla görülen tür Plasmodium vivax'dır, nadiren import vakalarda P. falciparum'da görülmektedir. 1926 yılında başlayan eradikasyon çalışmaları ile vaka sayıları oldukça azalmıştır. Ancak, seyahat, göçler ve programdaki aksaklıklar dolayısıyla import vaka sayıları artmaktadır. Sıtma açısından dünyada tropical, subtropical ülkelere, ülkemiz için Güneydoğu Anadolu ve Çukurova gibi endemik bölgelere seyahat öyküsü olan her ateşli olguda önce sıtma düşünülmelidir. Bu çalışmada yurt dışında çalışma öyküsü olan dört import olgunun epidemiyolojik ve klinik özelliklerinin değerlendirilmesi amaçlanmıştır. (Turkiye Parazitol Derg 2013; 37: 161-4)

Anahtar Sözcükler: Plasmodium falciparum, P. vivax, sıtma, ateş

Geliş Tarihi: 21.12.2012

Kabul Tarihi: 26.04.2013

\section{ABSTRACT}

Malaria, as it has been during history, is an important parasitic infectious health problem nowadays. In Turkey, the most common kind of malaria is Plasmodium vivax, and P. falciparum is rarely observed in import events. After eradication activities started in 1926, the number of cases dramatically decreased in our country. However, the number of import cases is increasing as a result of tourism, migration, and deficiency in the eradication program. In tropical and sub-tropical regions and in endemic regions of Turkey such as South-Eastern Anatolia and Çukurova, in every feverish phenomenon, malaria is the first disease to be considered. The purpose of the present study is to evaluate clinical epidemiological characteristics of the four import patterns in foreign studies. (Turkiye Parazitol Derg 2013; 37: 161-4)

Key Words: Plasmodium falciparum, P. vivax, malaria, fever

Received: 21.12.2012

Accepted: 26.04 .2013

\section{Giriş}

Sitma; P. vivax, P. ovale, P. malariae ve P. falciparum'un etken olduğu, anofel cinsi sivrisineklerin vektör olduğu bir infeksiyondur. Semptomları periyodik ateş, titreme, anemi ve splenomegalidir (1-3). 2010 yılında dünyanın 106 endemik ülke ve bölgesinde yaklaşık 216 milyon sıtma vakası tespit edilmiştir. Ölümle sonuçlanan vakaların büyük çoğunluğu (\%91) özellikle Afrika ülkelerinde ve ağırlıklı olarak 5 yaş altındaki çocuklarda görülmüştür (4). Dünyada ölüm nedenleri arasında ilk onda, Afrika da ise ikinci sırada yer almaktadır (4-6). Tanı, Plasmodiumların çeşitli formlarının kalın damla, ince

\section{Bu yazı 13-17 Mart 2013 tarihleri arasında Antalya'da gerçekleşen XVI. Türk Klinik Mikrobiyoloji ve Infeksiyon Hastalıkları Kongresi (Klimik 2013)'de sunulmuştur.}

This article is presented at XVI. Turkey Clinical Microbiology and Infectious Diseases Congress that is organised between 13-17 March 2013 in Antalya.

Yazışma Adresi / Address for Correspondence: Dr. Emine Parlak, Atatürk Üniversitesi Tıp Fakültesi, Enfeksiyon Hastalıkları ve Klinik Mikrobiyoloji Anabilim Dalı, Erzurum, Türkiye Tel: +90442 2360186 E-posta: eparlak1@yahoo.com doi:10.5152/tpd.2013.36 
yaymada görülmesiyle konur. Tedavi ve korunmada hastalığın alındığı bölge ve direnç önemlidir $(2,3,7)$. Sıtma, dünyanın her yerinde görülebilir. Anofellerin yaşamadığı yerlerde ise import vaka olarak görülür. Bölgemizdeki iklim nedeniyle anofel ve larvaların yaşayamaması nedeniyle sporadik vakalar görülmektedir. Endemik bölgelere seyahat öyküsü olan klinik olarak uyumlu her hastada öncelikli olarak sıtma düşünülmelidir (5). Bu yazı; eğitime, korunmaya, ülkeler arası işbirliğinin önemine ve endemik olmayan bölgelerde import sıtma olgularına dikkat çekmek amacıyla hazırlanmıştır.

\section{OLGU SUNUMLARI}

\section{Olgu 1}

Atatürk Üniversitesi Tıp Fakültesi Dahiliye kliniğinde ateş ve anemi tetkik tanısı ile izlenen 40 yaşında erkek hasta, periferik yaymasında sıtma paraziti görülmesi üzerine Enfeksiyon Hastalıkları kliniğine devir alındı. Hikâyesinden işçi olarak Sudanda bir yıl çalıştığı, bu dönemde sıtma geçirdiği, kinin ve artemeter tedavi aldığı öğrenildi. Türkiye'ye döndükten birkaç gün sonra şikâyetleri başlamış. Hastanın kabulünde ateş, üşüme, titreme, halsizlik ve eklem ağrıları rahatsızlığı vardı. Fizik muayenesinde ateş; 37,7 C, nabız; 86/dakika ve kan basıncı 120/75 mmHg olarak saptanmıştır. Karaciğer kot altında midklavikular hattan $2 \mathrm{~cm}$, dalak kot altından 2-3 cm palpabldı. Traube alanı kapalı olarak saptandı. Diğer sistem muayeneleri normal idi. Hemogram değerlendirilmesinde hemoglobin 10,7 g/dL, lökosit 5100/mm ve trombositler $111000 / \mathrm{mm}^{3}$ olarak bulundu. Biyokimyasal incelemelerinde total bilirubin: 1,1 mg/dL, albumin: 3,3 mg/dL AST: 25 IU/I, ALT: 25 IU/I, GGT: 44 IU/L ve LDH: 314IU/I saptanmıştır. Ince yaymasında taşlı yüzük formasyonu şeklinde, Plasmodium sp. trofozoitleri görüldü. Ancak parazitin türüne karar verilemedi. WHO tarafından klorokine dirençli bölge olarak kabul edilen Sudan'dan geldiği için tedavisi buna göre düzenlendi. Hastanın yanında getirdiği artemether adlı ilaç üç gün kullanıldı. Glukoz altı fosfat dehidrogenaz enzimi normaldi. Kliniği tipik olmadığı için, hipnozoit, reinfeksiyon veya relaps olabileceği düşünülerek, artemeter tedavisi tamamlandıktan sonra, Primakin 14 gün verildi. Takiplerinde ateşi olmadı, yaymada parazit görülmedi ve anemisi düzeldi. Tedaviye cevap veren hasta iyileşme ile taburcu edildi.

\section{Olgu 2}

Yirmi dört yaşında bayan hasta 6 gündür devam eden yüksek ateş, baş ağrısı, üşüme, titreme ve bol terleme ile kliniğimize başvurdu. Hikâyesinden bir yıldır Nijerya'da öğretmenlik yaptığı ve sekiz gün önce Türkiye'ye döndüğü öğrenildi. Anamnezinde yurda döndükten iki gün sonra başlayan ve nöbetler şeklinde $39^{\circ} \mathrm{C}^{\prime}$ yi geçen ateşi vardı. Serviste yapılan fizik muayenesinde ateşi $39,3^{\circ} \mathrm{C}$, tansiyonu 100/60 mmHg ve nabız 112/dakika olarak ölçülmüştür. Traube alanı kapalıydı. Hepatosplenomegalisi vardı. Yurt dışı çıkışı öncesi profilaksi ve tedavi almamıştı. Hemogram değerlendirmesinde hemoglobin 9,3 gr/dL, lökosit 2100/ $\mathrm{mm}^{3}$ ve trombosit $38000 / \mathrm{mm}^{3}$ olarak bulundu. Biyokimyasal tetkikleri ise albumin: 2,7 gr/dL, total bilirubin: 0,8 mg/dL, AST: 57 IU/I, ALT: 68 IU/I, GGT: 184 IU/L, LDH: 573 IU/I, CRP 96 gr/dL ve sedimantasyon 57/saat saptandı. Idrar kültüründe Klebsiella pneumoniae (Genişlemiş spektrumlu beta laktamaz pozitif) üredi. Alınan kan örneğinde kalın damla ve ince yayma incelemesi yapıldı. Giemsa ile boyandı. P. falciparum ile uyumlu trofozoitler görüldü. Hastaya kinin ve tetrasiklin tedavisi verildi. Klinik ve parazitolojik iyileşme görülünce şifa ile taburcu edildi.

\section{Olgu 3}

Otuz iki yaşında erkek hastaya pnömoni, üst solunum yolu infeksiyonu ve soğuk algınlığı düşünülerek devlet hastanesinde antibiyotik tedavisi başlanmış. Üç dört gün ilaçları kullanmasına rağmen ateşi düşmeyen hasta polikliniğimize başvurdu. Hikâyesinde yedi ay Afrika da çalıştığı, altı gün önce Türkiye'ye dönüş yaptığı ve dört gün önce şikâyetlerinin başladığı öğrenildi. Üşüme, titreme ile yükselen, iki üç saat süren $40-41^{\circ} \mathrm{C}^{\prime}$ yi bulan ve bol terleme ile düşen ateş, iştahsızlık ve bulantısı vardı. Seyahat öncesi profilaksi kullanımı ve orada tedavi öyküsü yoktu. Yapılan fizik muayenesinde ateş; $39,7^{\circ} \mathrm{C}$, nabız; $100 / \mathrm{dk}$ ve kan basıncl; $110 / 60 \mathrm{mmHg}$ olarak saptandı. Cilt ve konjuktivalar soluk. Karaciğer kot altından 2-3 $\mathrm{cm}$ ve dalak $3 \mathrm{~cm}$ palpabldı. Hematolojik değerlendirmesinde; hemoglobin: 10,3gr/dL,, lökosit: 2900/ $\mathrm{mm}^{3}$ ve trombosit: 42000/ $\mathrm{mm}^{3}$ olarak bulundu. Biyokimyasal tetkikleri ise total bilirubin: 1,15 mg/dL, AST: 64 IU/I, ALT: 65 IU/I, GGT: 192 IU/L, LDH: 478 IU/l, albumin 3,0 gr/dL olarak saptand. Hastadan kalın damla ve ince yayma yapıldı giemsa ile boyandıktan sonra değerlendirildi. Preparatlarda çok fazla sayıda genç trofozoitler gözlendi. P. vivax tanısıyla hastaya tedavi olarak klorakin ve primakin tablet başlandı. Ateşleri normale indi. Klinik ve laboratuar olarak iyilik haliyle taburcu edildi (Resim 1, 2).

\section{Olgu 4}

Yirmi sekiz yaşında erkek hasta Afrika'da sekiz ay bulunmuş. Türkiye'ye döndüğünde günde iki kez bol terleme ile düşen ateşi $\left(40^{\circ} \mathrm{C}^{\prime}\right.$ ye ulaşan) olmuş. Halsizlik, iştahsızlık, bulantı, üşüme, titreme eklenmiş. Ateşlerin düştüğü dönemlerde iştahı kısmen açılıyor ve kendini iyi hissediyormuş. Bu şikâyetlerle devlet hastanesinde üç gün doksisiklin verilerek izlenmiş. Trombositleri düşmeye devam eden hasta kliniğimize sevk edildi. Yurt dışı çıkışı öncesi

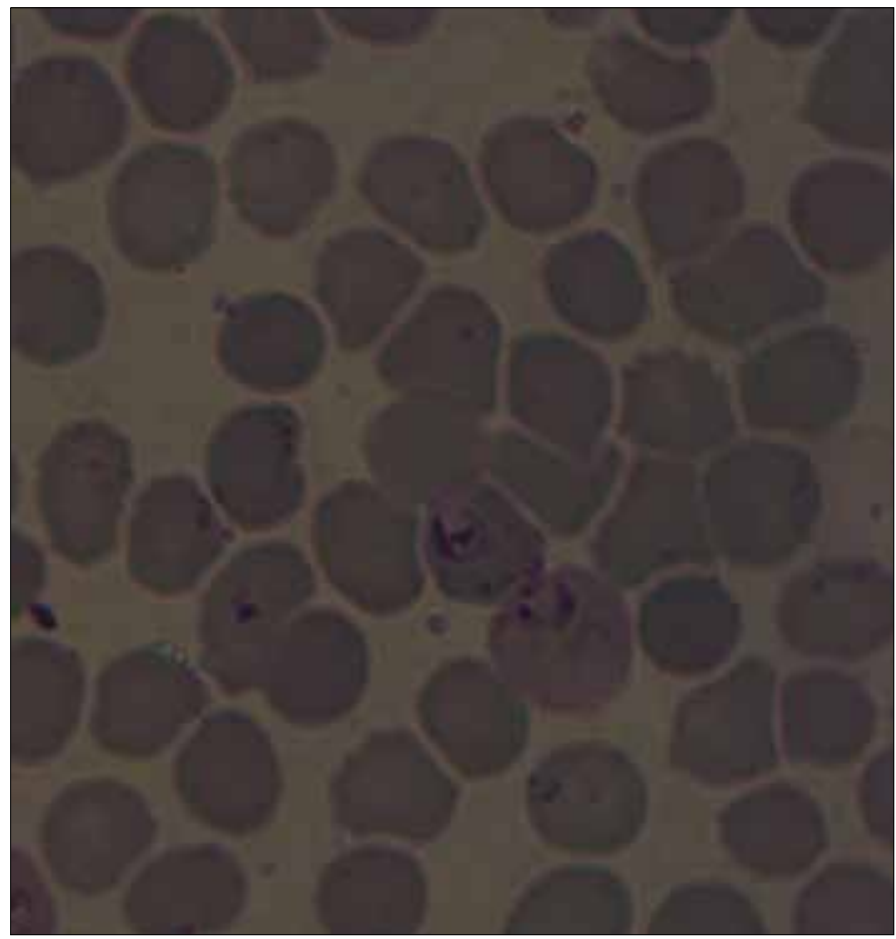

Resim 1. Ince yaymada Plasmodium gametositleri 
ismini bilmediği bir aşı yapılmış. Orada çalıştığı sürede her ay iki üç gün süren ateşli hastalığı oluyormuş. Yatırılarak beş, altı kez tedavi verilmiş. Fizik muayenesinde ateş: $39,8^{\circ} \mathrm{C}$, nabız: 96 ve TA: $110 / 70 \mathrm{mmHg}$ olarak değerlendirilmiştir. Karaciğer kot altında midklavikular hattı $2 \mathrm{~cm}$, dalak kot kavsini $3-4 \mathrm{~cm}$ geçiyordu. Traube alanı kapalı idi. Hemogram değerlendirmesinde hemoglobin: 9,8 $\mathrm{gr} / \mathrm{dL}$, lökosit $2900 / \mathrm{mm}^{3}$ ve trombosit $26000 / \mathrm{mm}^{3}$ olarak bulundu. Biyokimyasal tetkikleri ise total bilirubin: 0,72 mg/dL, AST: $41 \mathrm{IU} / \mathrm{l}$, ALT: $21 \mathrm{IU} / \mathrm{l}, \mathrm{GGT}: 21 \mathrm{IU} / \mathrm{L}, \mathrm{LDH}: 646 \mathrm{IU} / \mathrm{l}$, albumin 2,6 gr/dL, sedimantasyon 38/saat, CRP 79,2 ve diğer parametreleri normal olarak saptandı. Hastaya 4 kez random trombosit verildi. Kan örneğinde kalın damla ve ince yayma yapıldı. Wright ve giemsa ile boyandıktan sonra değerlendirildi. Taşlı yüzük şeklinde plasmodium trofozoitleri görüldü. Geldiği bölge itibarıyla sıtma etkeni olarak P. falciparum düşünüldü ve klorokine dirençli kabul edildi. Kinin şehrimizde bulunamadı, sağlık bakanlığından istendi. Bu sırada klorokin tablet ve doksisiklin tablet başlandı. Ateşleri $38^{\circ} \mathrm{C}$ üstünde seyretti. Hemoglobin ve trombositleri düşmeye devam etti. Tekrar yaymalarında parazit görüldü. Kinin tablet gelince 3×200mg/gün ve tetrasiklin 4x500mg/gün şeklinde tedavi değiştirildi. Tedavinin ikinci gününde ateşleri düştü. Dört ve altıncı gününde yapılan yaymalarında trofozoit görülmedi. Yedi güne tamamlanan tedavi kesildi. Trombositleri $300000 / \mathrm{mm}^{3 \prime}$ nin üstüne ve hemoglobin $13 \mathrm{gr} / \mathrm{dL}^{\prime} \ddot{n}$ üstüne yükseldi. Tam iyilik haliyle taburcu edildi.

\section{TARTIŞMA}

Sıtma dünyanın üçte ikisini etkileyerek çok sayıda insanın ölümüne neden olan eski hastalıklardandır (1). Eradikasyon çalışmaları ile sıtma vaka sayıları giderek azalmıştır. Son yıllarda dış kaynaklı vakalar, göçler, mevsimlik işçiler ve programdaki aksaklılar nedeniyle import olgularda bir artış olmuştur $(5,7,8)$. Ülkemizde Güney ve Güneydoğu Anadolu bölgelerinde endemik, diğer bölgelerde ise sporadik olarak görülmektedir (2). Sunduğumuz dört olguda da yurt dışına seyahat öyküsü vardı.

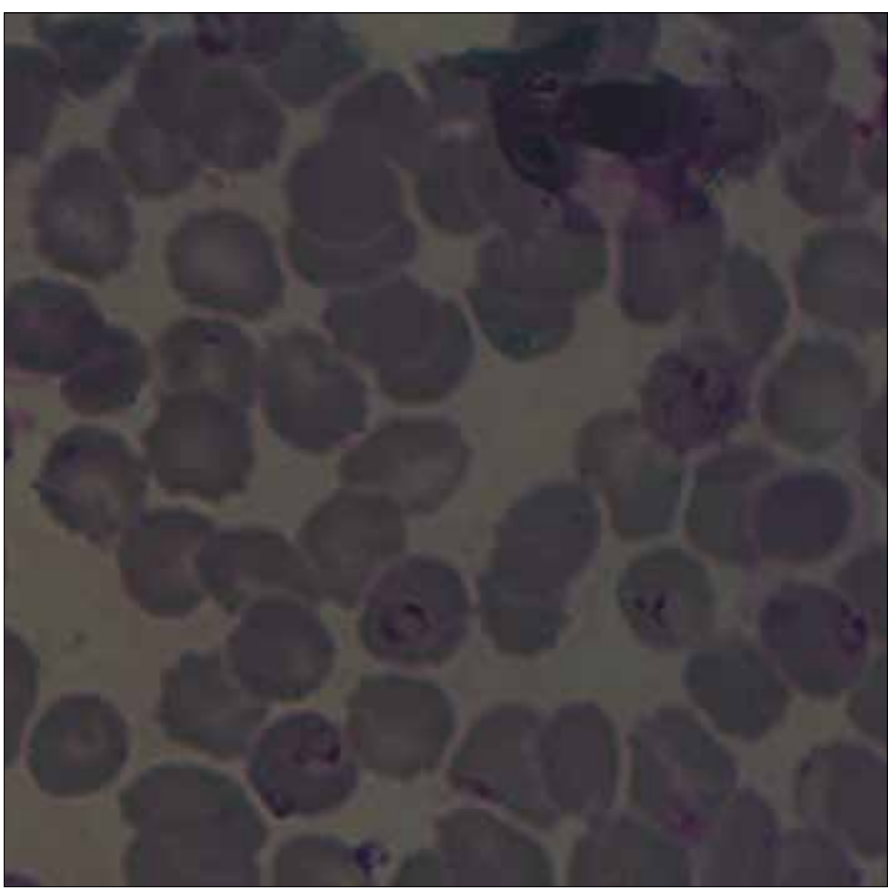

Resim 2. Olgunun kan yaymasında saptanan P. vivax gametositleri
Türkiye'de görülen $P$. vivax hafif seyreder ve hastalığa bağlı ölüm oluşturmaz. En ağır form oluşturan P. falciparum tropikal bölgelerde hastalık yapar. P. malariae subtropikal bölgelerin hastalığıdır. En nadir görülen tür olan P.ovale, sadece tropikal Afrika'da görülür. Sıtmanın, Afrika, Asya ve Latin Amerika gibi yaygın dağılımı olsa da, en sık Afrika da görülmektedir (1-4). P. falciparum'un etken olduğu olgularımızda serebral sıtma, böbrek yetmezliği ve başka bir komplikasyon görülmedi. Tam iyilikle taburcu oldular. Yurt dışı kaynaklı sıtma vakalarında etken genelde $P$. falciparum'dur $(5,7,8-10)$. P. vivax'ında etken olduğu vakalar rapor edilmiştir $(5,11,12)$. Biz vakalarımızda her iki etkeni de gördük.

Sıtma anofel cinsi sivrisineklerin yaşayabildiği $64^{\circ}$ kuzey ve $32^{\circ}$ güney enlemleri arasında kalan bölgelerde görülür $(3,7)$. Bulaşma yağış miktarına, infekte insanın varlığına ve ortam sıcaklığının $16-36^{\circ} \mathrm{C}$ olmasına bağlıdır (7). Sıtma hastalığının tek rezervuarı insandır (6). Hasta insanları bulup tedavi edersek ve sivrisinekleri ortadan kaldırırsak sıtmayı eradike etmek mümkün olabilir. Hasta sayıları mart ayından itibaren artmaya başlar, yaz ve sonbahar aylarında en yüksek sayılarına ulaşır. Sıtma olgularının en fazla görüldüğü aylar Haziran, Temmuz, Ağustos, Eylül ve Ekim aylarıdır $(3,5)$. Türkiye'de mevsimsel dağılım gösterir. Türkiye'de kışın görülen sıtma olguları, paraziti bulaş mevsiminde alan; ancak tedavi edilmeyen, tedavisini tam almayan ya da dış ülkelerden gelen hastalardır. Sıtma tropikal bölgelerde her mevsim ayn sıklıkta görülür (6). Bizim olgularımızın biri 2011, diğer üç olgu 2012 yılında başvurdu. Mayıs, Temmuz, Ağustos ve Kasım aylarında izlendiler. Bölgemizde iklim nedeniyle sıtma sporadik vakalar halinde görülür. Çoğunlukla vakalar dış ülke kaynaklıdır ve yaşanan en önemli problem tanı ve tedavi sorunlarıdır.

Sıtmada inkübasyon dönemi türe göre değişmekle birlikte 2-4 haftadır. Hastalarda üşüme, titreme, yüksek ateş, baş ağrısı, karın ağrısı, bulantı, kusma ve halsizlik vardır. Nöbetler şeklinde ateş (periyodik ateş) en önemli özelliğidir. Düzenli aralıklarla gelen ateş nöbetleri $P$. vivax, $P$. ovale'de 48 saat de bir, $P$. malariae'da 72 saat de bir görülür. $P$. falciparum sıtmasında 48 saat de bir siklus olsa da hastaların çoğunda düzensiz intermittan ateş paterni vardır. Ayrıca taşikardi, hipotansiyon, öksürük, sırt ağrısı, ishal, şuur bozukluğu, terleme ile ateşin düşmesi, halsizlik ve uyku hali görülür. Yarı immun kişilerde periyodisite olmayabilir. Anemi, trombositopeni, splenomegali, hepatomegali, sarılık, petesi, konjuktival kanama ve herpes labialis görülebilir. Semptomları periyodik olmayan olgularda da sıtma düşünülmelidir (1-3). Olgularımızın hepsinde ateş, titreme, terleme, halsizlik, hepatosplenomegali, anemi, lökopeni ve hafif transaminaz yüksekliği tesbit edildi. İlk olgu dışında diğerlerinde trombositopenide vardı.

Sıtmanın kesin tanısı, periferik kandan hazırlanan kalın damla, ince yayma preparatında parazitin görülmesi iledir $(2,3)$. Yapımı kolay olmasına rağmen tecrübe gerektiren bir incelemedir. Vakalarımızda sıtma trofozoitlerini görerek tanı koyduk.

Endemik bölgelerden gelen sıtma hastalarına o bölgenin ilaç direncine göre tedavi verilmelidir $(5,13)$. Sıtma tedavisinde kullanılan başlıca ilaçlar: Kinolin türevleri (kinin, klorokin, meflokin, primakin), antifolatlar (sulfadoksin/primetamin), artemisin ve atovakon olarak gruplandırılabilir $(2,14)$. Komplike $P$. falciparum 
da önerilen tedavi kinidin glukonatdır. Klorakin dirençli olanlarda Kinin sülfat ve primetamin veya sulfadiazin veya sulfisaksazoldür. Sülfanomid-primetamin dirençlilerde kinin sülfat- tetrasiklin veya klindamisin önerilmektedir $(1,2,15)$. Tedavi olarak $P$. vivax olgularına Sıtma Savaş Daire Başkanlığı tarafından önerilen klorokin + primakin sağaltımı uygulandı ve yanıt alındı. Son vaka ilaç olmadığı için kullandığımız klorokine cevap vermedi. Kan değerleri düştü, ateşleri devam etti. Sıtma için klorokin dirençli bölgeden geldiği için tedavi değiştirildi. P. falciparum olgularımızda kinin+ tetrasikline cevap alındı.

Endemik bölgelere seyahat edenlere kemoproflaksi başlanmalı ve döndükten sonra dört hafta daha devam edilmelidir. Bu amaçla falciparum sıtmasında, gebelerde ve çocuklarda da güvenle kullanılabilecek ilaç klorakindir. Klorakin dirençli endemik bölgeye gidenlere ise meflokin veya tetrasiklin önerilir $(1,2)$. Sıtmanın yayılımını önlemek için endemik bölgelere seyahat edecek olan kişilere; koruyucu ilaç kullanılması, sivrisineklere karşı bireysel tedbirlerin alınması (sineklik, cibinlik ve sinek kovucu ürünler kullanmaları gibi), eğitimlerin verilmesi ve ateşi olan hastaların erken tanınması anahtar uygulamalardır $(8,15)$. Olgularımızdan seyahat öncesi kemoproflaksi alan yoktu. Çalışmak için uzun dönem kalan kişilerde koruyucu önlemlere uyulması kemoproflaksiden daha önemlidir.

\section{SONUÇ}

Bir ülke ve bölgede, sıtmayı kontrol altına almanın en etkili ve kolay yolu hastaları bularak erken tanı ve tedavisini yapmaktır. Ülkeler arası işbirliği, eğitim, kontrol programları çok önemlidir. Değişik ülkelerden gelen sıtma olgularında bölgenin ilaç direncine uygun tedavi verilmelidir. Endemik olmayan bir bölgede import vakaların görülebileceğini belirtmek istedik.

\section{Çıkar Çatışması}

Yazarlar herhangi bir çıkar çatışması bildirmemişlerdir.

Hakem değerlendirmesi: Dış bağımsız.

\section{Yazar Katkıları}

Fikir - E.P., M.P.; Tasarım - E.P.,M.P.; Denetleme - E.P.,M.P.; Kaynaklar - E.P., A.E.; Malzemeler - E.P., A.E.; Veri toplanması ve/ veya işlemesi - E.P., A.E.; Analiz ve/veya yorum - E.P., Y.Ç.; Literatür taraması - E.P., M.P.; Yazıyı yazan - E.P., A.E.; Eleştirel inceleme - E.P., M.P.; Diğer - E.P., Y.Ç.

\section{Conflict of Interest}

No conflict of interest was declared by the authors.

Peer-review: Externally peer-reviewed.

\section{Author Contributions}

Concept - E.P., M.P.; Design - E.P.,M.P.; Supervision - E.P.,M.P.; Funding - E.P., A.E.; Materials - E.P., A.E.; Data Collection and/or Processing - E.P., A.E.; Analysis and/or Interpretation - E.P., Y.Ç.; Literature Review - E.P., M.P.; Writing - E.P., A.E.; Critical Review E.P.,M.P.; Other - E.P., Y.Ç.

\section{KAYNAKLAR}

1. Fairhust RM, Wellems TE. Plasmodium species (malaria). Mandell GL, Bennett JE, Dolin R, eds. Mandell, Douglas and Bennett's Principles and Practise of Infectious Diseases. 7th ed. Philaldelphia: Churchill Livingstone 2010.p.3437-62.

2. Dündar iH. Sıtma. Topçu AW, Söyletir G, Doğanay M, eds. Infeksiyon Hastalıkları. İstanbul: Nobel Tıp Kitabevleri 2008.p.927-46.

3. Kuman H A, Altıntaş N. Plasmodium'lar. Protozoon Hastalıkları. Izmir: Ege Üniversitesi Basımevi 1996.s.152-80.

4. World Health Organization. World malaria report 2011, WHO Press, Geneva, Switzerland.

5. Mert A, Tabak F, Özaras R, Öztürk R, Aktuğlu Y. Sıtma: Otuz üc Olgunun Değerlendirilmesi. Flora 2001; 6: 118-25.

6. Akdur R. 1997. Sıtma Eğitim Notları. Ankara, T.C Sağlık Bakanlığı Sıtma savaş Daire Başkanlığı Yayını.

7. Çetinkaya Z, Özçelik R. Afyon'da Sıtma Epidemiyolojisi. Türkiye Parazitol Derg 2004; 28: 77-9.

8. Yaman M, Durgut R. Hatay bölgesinde sıtmanın yaygınlığı. Türkiye Parazitol Derg 2003; 27: 179-83.

9. Önlen Y, Çulha G, Ocak S, Savaş L, Güllü M. Yurtdışı Kökenli Plasmodium falciparum Sitması: Dört Olgu Sunumu. Türkiye Parazitol Derg 2007; 31: 256-9.

10. Karaman Ü, Atambay M, Yaşar S, Çolak C, Miman Ö, Daldal N Malatyaıda son yedi yıl içindeki sıtma olguları. Türkiye Parazitol Derg 2007; 31: 245-8

11. Ser Ö, Çetin H. Antalya Illinde 2001 ile 2011 Yılları Arasındaki Sıtma Vakalarının Değerlendirilmesi. Turkiye Parazitol Derg 2012; 36: 4-8. [CrossRef]

12. Karaman U, Atambay M, Yaşar S, Colak C, Miman O, Daldal N. Malatyarda Son Yedi Yıl İçindeki Sıtma Olguları. Türkiye Parazitol Derg 2007; 31: 245-8.

13. Mert A, Tabak F, Kuyumcu M, Dumankar A, Polat E, Yücel A, ve ark. Klorokine Duyarlı Bir Plasmodium falciparum Sitma Olgusu. ANKEM Derg 1995; 9: 195.

14. Ergüven S. Kan ve Doku Protozoonlarına Karşı Kullanılan Yeni Illaçlar. ANKEM Derg 2012; 26: 108-15.

15. Genton B, D'Acremont V. Malaria Prevention in Travelers. Infectious Disease Clinics Of North America. Ed.by Moellering Jr R C. September 2012; 26.p.637-55. 